\title{
O homem em farrapos: a experiência da moda em Flávio de Carvalho
}

\author{
Victor da Rosal \\ I - UNESP \\ São José do Rio Preto (SP), Brasil
}

Resumo: O artigo analisa em detalhe um conjunto de textos de Flávio de Carvalho sobre moda, publicados em 1956 e reeditados em 2010, em perspectiva com dois teóricos contemporâneos que também se dedicaram a pensar sobre o assunto: Emanuele Coccia e Boris Groys. A ideia central é pensar a figura do "homem em farrapos", figura que o próprio Flávio desenvolve por meio de uma série de reflexões sobre a história do vestuário, como contribuição ao debate vanguardista em torno do "homem novo". Por meio dela, é possível compreender outro conceito central proposto pelo autor, o de Unissexo, e também revisitar a sua célebre performance realizada a partir da criação de um new look. Dessa forma, o artigo procura debater não apenas o lugar que a moda ocupou na trajetória desse artista singular, mas também chamar atenção para a pertinência e a atualidade do pensamento de Flávio a respeito de tal debate.

Palavras-chave: Flávio de Carvalho; moda; experiência; farrapo.

Abstract: The man in rags: fashion experience in Flávio de Carvalho - The article analyzes in detail a set of writings by Flávio de Carvalho about fashion, first published in 1956 and then reissued in 2010, in perspective with two contemporary theorists who also dedicated themselves to look into the subject: Emanuele Coccia and Boris Groys. The central idea is to explore the figure of the "man in rags", a figure that Flávio himself develops through a series of reflections on the history of clothing, as a contribution to the avant-garde debate around the "new man". It enables an understanding of another central concept proposed by the author, that of Unisex, and also to revisit its celebrated performance from the creation of a new look. Thus, the article proposes to debate not only the spot occupied by fashion in the trajectory of this singular artist, but also to draw attention to the relevance and topicality of Flávio's works regarding such debate.

Keywords: Flávio de Carvalho; fashion; experience; rag. 


\section{A moda e o novo}

Em 1993, o designer de moda Hussein Chalayan realizou um desfile que logo se tornou um marco na história da moda recente. Três meses antes do evento, o estilista enterrou os vestidos da coleção no jardim de sua casa e desenterrou somente alguns dias antes do desfile, dando a eles uma aparência encardida. As peças, que chegaram a apodrecer em algumas partes, além de carregar o peso e a textura da terra, a própria sujeira do barro, perderam também as qualidades mais nobres que a alta costura proporciona. Em suma, se transformaram em espécies de trapos, roupas velhas, usadas e sem valor.

Por um lado, Chalayan parece se apropriar do traço talvez de maior radicalidade que a moda oferece à história: sua capacidade de alteração incessante, sua fragilidade diante da ação do tempo. Pode-se sugerir a leitura de que, por um lado, Chalayan faz uma crítica ao sentido de efêmero que é iminente a toda moda, seu caráter banal e passageiro. Por outro, talvez seja interessante também imaginar, além de mais difícil, que os vestidos enterrados se apropriam e nos colocam, mais além do valor, diante daquilo que há de mais paradoxal no próprio conceito de moda: o novo. Na primeira leitura, trata-se de uma crítica ao sistema da moda; na outra, é possível concluir que Chalayan faz a moda reviver por meio de seu próprio paradoxo entre velho e novo.

O procedimento que Hussein Chalayan realiza parece dizer respeito a uma espécie de aceleração temporal. O tempo de resistência do vestido debaixo da terra, à sua maneira, pode ser percebido como a própria resistência da moda - que seria fraca ou efêmera diante da história. Ou seja, assim como a moda, o vestido torna-se velho rapidamente. Mas mesmo esfarrapado ele é recebido como novidade. A presença do vestido em farrapos, com o peso do tempo e as marcas da terra estampadas no tecido, nos diz também sobre a impossibilidade de controlar o presente. Nesse sentido, a moda poderia ser definida como o descontrole do tempo histórico. Sua posição na história se dirige ao ponto em que não há mais verdade universal que possa controlar nossas vidas. Afinal de contas, o que o desfile Chalayan parece evidenciar, à medida que entrega sua coleção de roupas ao acaso do tempo, lembrando a criação de poeira de Marcel Duchamp, não é outra coisa senão isto: o futuro não é previsível. E esse talvez seja um legado filosófico que a moda nos deixou.

O crítico de arte Boris Groys, em sua reflexão sobre o novo, Du nouveau, dedica um belíssimo fragmento à moda: "Le nouveau et la mode". Groys argumenta que apesar das condenações - injustas, em sua maneira de pensar - que a moda sofreu tanto na modernidade quanto nas últimas décadas, ela também é investida, sobretudo pela sua forma de alteração contínua e busca pelo novo, por um traço revolucionário: “Com efeito, a moda é radicalmente anti-utópica e antitotalitária, pois sua transformação incessante testemunha que o futuro não é previsível, que ele não pode escapar à mudança histórica, e que não existe verdade suscetível de determiná-la integralmente" (GROYS, 1995, p. 47). 
Para Groys, a condenação que se faz à moda parte justamente da crença em uma verdade universal, em uma verdade capaz de determinar o presente e o futuro em sua integralidade, ou então da ideia de que o dever do pensamento é se preservar da mudança histórica.

A moda, pelo contrário - seja na arte, no traje, nos hábitos ou até mesmo nos sistemas de pensamento - se apresenta de maneira inacabada e provisória. Por isso ela não é um produto, mas um processo. Como procura pelo novo, a moda aparece para Groys como um meio no qual é possível se liberar do poder do passado: "Mas, sobretudo, o novo oferece ao autor individual a possibilidade de afirmar sua própria vida como um valor no tempo histórico, e se liberar do poder do passado" (GROYS, 1995, p. 50). Para o crítico, a moda é capaz de tornar instável as igualdades aparentes de seu tempo, introduzindose entre as camadas da história como uma diferença essencial, mas sempre provisória, no meio de todas as diferenças parciais: "Se todas as coisas não se distinguem uma das outras senão parcialmente, permanecendo, no fim das contas, iguais, a moda viola esta igualdade aparente, ressaltando como mais essencial e como tendo mais valor uma diferença qualquer entre todas as diferenças parciais" (GROYS, 1995, p. 47). Daí seu caráter subversivo e antitotalitário.

Groys pensa diferente do senso comum também ao argumentar a respeito das marcas que a moda imprime na memória cultural, que é afinal o tema de seu ensaio: "assim, contrariamente a uma opinião difundida, é justamente aquilo que está na moda hoje que tem maiores chances de ser preservado no futuro" (GROYS, 1995, p. 48). Em suma, era a filosofia de Kant que estava na moda no século XVIII. E diferentemente da ideia - a rigor verdadeira - de que a moda acaba por construir sistemas rígidos de diferenciação, se rendendo a uma atitude social elitista e a uma hierarquia de valores, hierarquia válida e reconhecida no interior de um grupo determinado, Groys prefere pensar a moda como um conceito dotado de uma força que, de maneira intempestiva, se direciona contra as regras de uma tradição estável. A moda e o novo, nesse caso, seriam sinônimos principalmente pelos desafios que oferecem aos percursos do tempo histórico.

\section{"A imaginação das ruas"}

Flávio de Carvalho, em seus ensaios sobre o assunto, publicados originalmente no jornal Diário de São Paulo durante o ano de 1956, e recentemente reunidos em livro, sugere "quatro conclusões fundamentais" - na verdade, trata-se de quatro teses sobre a moda - que irão nortear a sua reflexão. Uma delas, a terceira, consiste na ideia de que a moda se processa de baixo para cima: "As grandes mutações da moda acontecem de baixo para cima na hierarquia social e, quando o alto é atingido, as mutações se disseminam como moda" (CARVALHO, 2010, p. 13). Para Flávio, a moda nasce do sofrimento e da dor, ou seja, da "imaginação das ruas", talvez da improvisação e da espontaneidade, e não nas Cortes, nos palácios e nos ateliês de alta costura. 
No texto intitulado "A grande imaginação do limite vagando pelas ruas", mas também em outros textos de sua coluna - pois Flávio de Carvalho parece construir um pensamento em espiral, sempre retornando ao ponto de onde partiu - o autor explica melhor a sua hipótese. Para o autor, é a loucura e o sonho "de homens e mulheres que perderam o controle dos seus desejos e das suas angústias e que se apresentam vagando pela rua, discursando histericamente para um público às vezes imaginário", enfim, é de tal imaginário que surge a grande moda (CARVALHO, 2010, p. 16). Quer dizer, são os "marginais descontrolados" que exibem "profuso aparato e ornamento, cobrem-se com flores e fitas, e cores e panos diversos que se desdobram, agradavelmente", são eles os detentores da grande imaginação. A grande moda, dessa maneira, seria uma espécie de antimoda.

A tese de Flávio de Carvalho tem consequências interessantes e radicais. Para o autor, o que define a moda é o movimento - e nesse caso Flávio não está muito longe de Boris Groys, para quem a moda é a história sob a forma da imprevisibilidade. Um dos motivos pelos quais a grande moda nasce do ponto mais baixo da hierarquia social, segundo a hipótese de Flávio, refere-se a sua ligação com as necessidades imediatas e materiais do trabalho. E o movimento, mesmo no sentido mais comum da palavra, é a principal dessas necessidades. Ou seja, a necessidade do movimento produz força, desejo e, portanto, provoca alteração. Em outro de seus textos, o autor argumenta que "As mutações da moda são facilidades para o movimento do corpo e para o exercício do trabalho e por esses motivos eram geradas nas classes que mais exerciam essas atividades, isto é, o povo, o agricultor, o escravo, o soldado" (CARVALHO, 2010, p. 47). Trata-se de pensar na possibilidade do movimento que a roupa oferece para o próprio corpo, assim como para o movimento da história.

A imagem do "homem em farrapos", nesses termos, que é recorrente em diversos textos de Flávio de Carvalho sobre o assunto, pode ser entendida como a principal figura dessa hipótese. O homem em farrapos, em suas palavras, "é um desclassificado, o totalmente sem classe, um posto de lado pela sociedade", ou então "o contrário do homem investido de autoridade, o contrário do homem uniformizado e o oposto do homem endurecido pela disciplina" (CARVALHO, 2010, p. 85). O farrapo, traje sem valor, fica no limite entre a roupa e a ausência de roupa, entre a cultura e o estado primitivo, o ruído e a linguagem articulada, enfim, entre o tabu e o totem. "O homem em farrapos é o homem a caminho do abandono da roupa, é o homem a caminho de uma vida idêntica à dos mamíferos inferiores", nos diz o autor (CARVALHO, 2010, p. 87).

Ao mesmo tempo, o farrapo servirá como modelo das modas mais estranhas e mais requintadas na história da elegância humana. O farrapo, vindo dos lugares sem classe, alcança também os reis e os deuses moribundos. Dessa maneira, o Imperador Carlos $\mathrm{V}$, representado em 1532 - assim como o rei Dom Sebastião, de Portugal - terá "as mangas, as calças e o gibão (...) compostos de panos cortado em tiras como se fossem trapos" (CARVALHO, 2010, p. 90). Certos trajes, de acordo com o autor, chegavam a ter cinco 
mil cortes e, diferentemente do que se pode imaginar, o farrapo tornou-se um recurso extremamente dispendioso e caro. A mesma coisa ainda acontece com a moda dos bobos da Corte, personagens que imitavam os reis na maneira de falar e de se vestir. É por meio da figura do farrapo que passa a existir toda uma ligação entre o rei em farrapos, o bobo do rei e o rei momo do Carnaval.

A moda em farrapos, à medida em que reaparece com as revoltas comunistas nos séculos XIII e XIV, quando populações camponesas viviam na mais absoluta miséria, vagando desabrigadas, com as roupas desgastadas e as pernas de fora, atinge também os soldados alemães, mais ou menos nos anos de 1400. "Esse aspecto permanecera visível o tempo suficiente para impressionar as hierarquias e sempre em primeiro lugar a que estava mais em contato com o faminto maltrapilho, isto é, o soldado destacado para reprimir as revoltas" (CARVALHO, 2010, p. 95). Dessa maneira, a morfologia do farrapo pode ser percebida por meio das roupas dos soldados: em alguns deles, a perna esquerda apresentará furos; em outros, as mangas também terão marcas de farrapos; e em outros casos até mesmo os gorros terão cortes simulando panos soltos. Ou seja, em diferentes momentos da história, as mais altas aristocracias, dos reis aos soldados - aliás, segundo a perspectiva de Flávio, são os soldados que fazem a ligação entre o povo e a nobreza -, adotam o traje esfarrapado durante longo período de tempo.

A moda em farrapos tem ainda outra consequência fundamental para a história da moda: a exibição das pernas. Com a apropriação do traje em farrapos pela nobreza, os homens da Corte passam a mostrar suas pernas. No período do Renascimento, o homem abandona as vestes talares, trajo característico da Idade Média, de origem romana, que cobria as pernas até os calcanhares, e incorpora os decotes. A mudança é brusca, diz o autor: "do talar pudico para as linhas das pernas moldadas com malha e inteiramente descobertas quase até a cintura" (CARVALHO, 2010, p. 99). No entanto, a mudança se tornou brusca na medida apenas em que alcança a nobreza, pois as pernas livres dos camponeses e dos artesãos - "que necessitava tê-las livres para o trabalho" - já podiam ser vistas "dois séculos antes".

A presença do farrapo na história da moda - farrapo, em francês, se diz guenille ainda teria importância na formação da cauda, elemento fundamental na indumentária de vários períodos da moda - e que, na leitura do autor, indica luto e ausência de procriação: "A palavra guenille, provavelmente um diminutivo do velho Gone que significava um vestido de cauda ou casaca, nos mostra que o farrapo ou guenille estava ligado ao rigor e ao luto da cauda (...)" (CARVALHO, 2010, p. 94). A passagem do farrapo para a cauda ainda se verifica em um costume da cultura judia que consiste em rasgar seus trajos durante os funerais para que se arrastem como longas caudas. "A palavra inglesa Gown, que significa vestido comprido, é sem dúvida derivado do velho Gone" (CARVALHO, 2010, p. 94). É possível entender de outra maneira, a partir da noção de "homem em farrapo", o motivo pelo qual o look tropical que Flávio elabora para desfilar pelas ruas 
de São Paulo, em outubro de 1956 - mais conhecido como new look, referência irônica a Christian Dior -, além de possuir vazamentos para a entrada de ar, guarda uma sutil semelhança com o traje do arlequim.

\section{Da exibição das pernas}

Ser tiranizado pela moda significa permanecer em equilíbrio.

Flávio de Carvalho

Nas últimas linhas de uma conferência realizada na capital pernambucana, em um Seminário de Tropicologia organizado por Gilberto Freyre no ano de 1967 - ou seja, mais de dez anos depois de seu desfile pelas ruas de São Paulo -, Flávio de Carvalho diz "duas palavras" sobre o look que desenvolveu; um traje "adaptado do trópico", segundo sua definição. São duas palavras apenas, mas duas palavras reveladoras, afinal, à medida em que Flávio volta a pensar sobre a elaboração de seu new look, faz também um movimento ao passado na releitura de alguns de seus textos, e ainda desfaz um mal-entendido a respeito de uma interpretação geral que se construiu da noção de "novo homem". Em resumo, é preciso esclarecer que Flávio não escreveu exatamente sobre "moda masculina". Pelo contrário, a afirmação de que Flávio está tratando exclusivamente de moda masculina acaba apagando aquilo que se apresenta como um dos conceitos mais radicais construídos ao longo de sua reflexão, mas que só aparece explícito em seus últimos textos: a noção de Unissexo.

Quando inventa seu new look e desfila pelas ruas de São Paulo, Flávio de Carvalho procura realizar, segundo afirma na conferência, dois desejos: primeiro, a construção de uma moda tropical, que deve ser necessariamente pensada para as ruas; e também um prognóstico. "A minha intenção de projetar um trajo adequado ao trópico era somente uma necessidade de modificação da indumentária, mas também era um prognóstico, foi um prognóstico feito 11 anos atrás, de acontecimentos que estão se iniciando hoje", diz (CARVALHO, 2010, p. 296). A rigor, sua performance se conjuga dentro de uma associação radical entre tempos distintos: um olhar para o passado, aos ossos do mundo, que é aqui a própria história da moda, e também uma procura pela transgressão, ou seja, a criação de conceitos para pensar o futuro. Ao descrever a peça com a qual desfilou, Flávio não deixa de enfatizar que ela é projetada de uma maneira que facilite justamente o movimento do corpo: válvulas no blusão permitiam o movimento dos braços e que, por sua vez, provocavam a renovação do ar; o saiote acima dos joelhos exibia as pernas; as meias de malha, também nas pernas, tinham a função de esconder as varizes, mas elas não impediam a circulação de ar; o blusão é aberto embaixo; e até mesmo a gola ao redor do pescoço, um substituto do colarinho, era frouxa e não impedia a circulação.

Para Flávio, o poder age de forma opressiva sobre a indumentária na medida em que imobiliza o corpo. Isso pode ser percebido, em sua leitura, por meio da indumentária 
religiosa, ou mesmo de algumas peças femininas, como a saia justa. Em uma reflexão sobre Joana D'Arc, Flávio se questiona sobre o significado de uma mulher, no século XV, usar calças: "Na persistência de Joana D'Arc em usar calças, mesmo quando encarcerada e quando recebia ordens de mudar para o trajo da mulher, encontramos uma manifestação da elasticidade sempre latente na mulher procurando um nivelamento ao sexo dominante", escreve. E conclui: "para alcançar esse nivelamento, [deve libertar] os movimentos da parte inferior do corpo, da cintura para baixo" (CARVALHO, 2010, p. 193). Ou seja, por meio da saia justa a mulher era inicialmente amarrada e paralisada; e mesmo no século XX, segundo Flávio, a saia justa aparece ainda como uma espécie de sobrevivência de amarras antigas, pois é uma forma de indumentária que dificulta o movimento.

A grande quantidade de paramentos, que Flávio de Carvalho chama de "empilhamento crescente da indumentária", também diz respeito a uma forma de poder. Quanto maior a classe hierárquica, maior o número e o peso dos paramentos. Isso seria claramente visível, por exemplo, na moda religiosa. Das ordens menores, que podem usar apenas uma túnica simples, sem qualquer acessório, até os arcebispos e finalmente o papa, o que se percebe é um empilhamento cada vez maior tanto de indumentárias quanto de acessórios. Por um lado, o homem em farrapos exibe os braços e as pernas, o corpo quase nu; por outro, o papa se apresenta como paradigma máximo da imobilidade. Ou seja, se existe uma espécie de paradigma da exibição das pernas, existe também, como antítese, o isolamento das pontas do corpo. É a conclusão a que Flávio de Carvalho chega quando observa as alterações do trajo religioso: "Estudando os trajos da hierarquia religiosa observa-se um importante fenômeno: o isolamento gradual do corpo, à medida em que a classe hierárquica se eleva" (CARVALHO, 2010, p. 153).

A religião é a imitação da morte, e será na construção de sua indumentária, pondo fim ao movimento e à exibição do corpo, que a morte se faz presente na história da moda. Há um texto em que o autor refaz uma espécie de genealogia da moda religiosa, texto intitulado justamente de "A imitação da morte - o isolamento do corpo", e ali observa que os trajos litúrgicos têm origem popular, como as túnicas sem cinto, mas vão sofrendo adições e modificações, principalmente do século IX ao século XII, que afinal preparam o corpo para o espetáculo da morte. Para Flávio, é no século IX que se completa o processo daquilo que ele chama de "simbolização hierárquica do trajo litúrgico" (CARVALHO, 2010, p. 157). Pedras preciosas, bordados e inúmeros paramentos, assim como a proteção das pontas do corpo, começam a ser usados por todos os bispos. Quanto mais alta a classe hierárquica, mais isolado se torna o corpo. "O isolamento máximo traz a imobilidade máxima na mais alta hierarquia. Imobilidade e altura hierárquica se confundem. Paradoxalmente a proteção ao movimento conduz à ausência de movimento", conclui (CARVALHO, 2010, p. 159).

Ora, o new look de Flávio, em seu desfile pelas ruas de São Paulo, espécie de happening conhecido como Experiência $n^{\circ} 3$, repete sua experiência anterior, quando o artista caminha contra uma procissão religiosa usando um boné. O que Flávio faz 
com seu trajo tropical é também uma espécie de invasão no meio de um debate entre dois paradigmas da moda, que são, a rigor, dois modos de pensar a cultura: o homem em movimento e o homem imobilizado, ou seja, a exibição das pernas e o isolamento das pontas do corpo. O new look de Flávio seria então uma provocação contra o trajo litúrgico, e a exibição das pernas se apresenta como a grande contribuição do homem em farrapos para a história da moda. De resto, há outra consequência que se pode depreender ainda de sua peça, justamente aquilo que Flávio apresentou na conferência como um prognóstico, mas que já estava sugerido em alguns de seus textos anteriores: o nivelamento entre masculino e feminino.

\section{"Unissexo"}

A história da moda testemunha também uma série de apropriações da indumentária masculina pelas mulheres e vice-versa. O último dos textos de Flávio de Carvalho sobre moda, mais do que esclarecedor, é também visionário. Nele, o autor esboça outro conceito que, assim como a noção de homem em farrapos, é central para entender seu pensamento e mesmo sua experiência de desfile com o new look. Para Flávio, o homem vive um momento que poderia ser imaginado como uma "Volta ao Útero", isto é, "a um momento no qual o sexo é quase indefinido", pois "os seus cabelos se apresentam compridos como os da mulher ou longos como eram usados na Idade Média, ele ostenta um decote e ornamentos e berloques que atualmente são usados por mulheres, e quando não usa barbas e é visto de uma certa distância torna difícil distingui-lo da mulher" (CARVALHO, 2010, p. 280). Por outro lado, a mulher, por meio da "exibição de formas nuas e adoção de indumentária masculina", segundo a teoria do autor, procura intensificar seu desejo de nivelamento com o sexo oposto.

Se for verdade que a moda do traje, entre todas as modas, é a que mais influência exerce sobre os homens porque diz respeito àquilo que está mais perto do seu corpo, então talvez o nivelamento dos trajes deva nos dizer algo além do trivial. Os movimentos de nivelamento levam a uma nova forma de compreensão da subjetividade e mesmo do erotismo que Flávio de Carvalho vai chamar de Unissexo, ou sexo único, forma que conduziria nossa relação com o corpo ao homossexualismo entre homens e mulheres. Nesse caso, diante da dissolução da família, que necessita da definição entre os gêneros para garantir o seu lugar, já que é fundada sobre a lógica da propriedade, a mulher deixaria de ser controlada por sua função procriadora e seria levada a pensar em outra forma de relação social. "O contato homem-mulher se processaria para prazer e negócios", escreve (CARVALHO, 2010, p. 282).

Em poucas palavras, a conquista da mulher, para Flávio, passa também por uma série de apropriações dos trajes masculinos. Na verdade, em vários momentos da história, homem e mulher se vestiram iguais. A necessidade de cobrir as partes inferiores 
do corpo com panos - principalmente as partes abaixo da cintura - surge nas sociedades primitivas não só como proteção contra o clima, mas também como forma de nivelamento, como "uma tentativa para eliminar a luta contra os sexos" (CARVALHO, 2010, p. 171). Mas também em períodos como o século XIII, quando ocorrem tentativas comunistas, homem e mulher se vestem com túnicas idênticas, assim como no período da Revolução Francesa. Outro detalhe interessante na história da moda é o revezamento entre homens e mulheres da maneira como se utiliza a altura da cintura: "A posição da cintura no homem e na mulher se revezam através da história: quando a mulher usa cintura baixa o homem usa cintura alta e vice-versa" (CARVALHO, 2010, p. 215).

O fim do "tratado de paz" entre homens e mulheres, no entanto, acontece quando o homem passa a usar calças, peça que facilita o movimento das pernas e explicita uma diferença, por meio do traje, entre os sexos. Na verdade, a calça pode ser percebida como uma tecnologia de dominação do masculino. "A calça ligada ao movimento das pernas, movimento que concedeu Visão Geográfica e Inteligência, passa a ser um atributo do homem e uma maneira de diferenciá-lo da mulher" (CARVALHO, 2010, p. 173). O primeiro registro de calças encontrado por Flávio de Carvalho remete ao século VII antes de Cristo, quando era usada por guerreiros, assim como pelos gregos duzentos anos depois. No texto que escreve sobre a origem popular da calça (CARVALHO, 2010), o autor refaz uma genealogia também dessa peça tão importante para a diferenciação dos sexos: de como ela atravessa a Era Cristã e passa pela Idade Média até chegar a Pantaleone, personagem que no século $X$ se torna uma espécie de santo padroeiro de Veneza e produz um personagem de comédia ligado à calça; enfim, de como a calça se torna uma peça versátil, usada por homens de todas as classes sociais, em momentos distintos da história, mas uma peça fundamentalmente masculina. Daí o caráter transgressor de Joana D'Arc, quando se apropria do uso da calça. No século XX, as mulheres voltam a usar a peça.

Por isso a noção de Unissexo, assim como a de homem em farrapos, é tão importante para as teorias da moda que Flávio de Carvalho desenvolve. Em seu new look, como estratégia inversa de nivelamento, Flávio abre mão da calça em favor da saia. Em ambos os conceitos está em questão um aspecto comum, uma associação que possui interesse para o seu pensamento: a de ausência de classe. Assim como o homem em farrapos - um ser "totalmente sem classe", em suas próprias palavras -, também a noção de Unissexo deseja apagar a linha demarcatória que separa o homem da mulher e, no limite, o humano do animal. Afinal, a noção de Unissexo não faz uma terceira categoria, e sim sugere uma ausência de categoria, uma nova forma de experiência e erotismo. O que nos faz concluir que o "novo homem" não é exatamente um homem. Só quem exibe a nudez do próprio corpo pode perder seus principais atributos para aprender a dançar. 


\section{"Forma fora de si"}

Somente quem sabe maquiar-se pode dizer eu.

Emanuele Coccia

Emanuele Coccia, em A vida sensível, define a moda como um sensível encarnado. "O que é de fato vestir-se senão incorporar um sensível exterior?", pergunta. Viver, para o filósofo, significa então "dar a ver". E pensar a experiência do sensível, portanto, consiste em imaginar uma imagem que se encontra em um lugar deslocado, em "outro lugar", um lugar que não é mais próprio, a exemplo da imagem já cindida no espelho. "Ser imagem significa estar fora de si mesmo, ser estrangeiro ao próprio corpo e à própria alma", escreve o filósofo (COCCIA, 2010, p. 23). Ou seja, ser imagem significa permanecer fora, em estado de exílio. E a moda então será a chave de seu ensaio porque, para que vida sensível seja pensável, é necessário pensar antes em uma espécie de intermediário, em uma mediação que pode ser um espelho ou uma roupa (COCCIA, 2010, p. 19).

Entre o corpo e a moda há uma distância que pode ser chamada de exílio. Flávio não está pensando em outra coisa quando afirma que a maneira de se vestir é o que há de mais influente sobre o homem porque "é aquilo que está mais perto de seu corpo". E quando afirma: "A moda se apresenta como aquilo que mais se aproxima ou mais se funde com o que há de fantástico na imaginação do homem" (CARVALHO, 2010, p. 16). Ora, estar perto do corpo significa que se está em outro lugar. O esforço de toda reflexão que Flávio de Carvalho elabora sobre moda é uma tentativa também de responder às perguntas que abrem o ensaio de Coccia: "Qual é a maneira de ser da forma em exílio em relação ao próprio lugar natural? Como a nossa forma existe no espelho? Em suma, qual é o ser-no-mundo definido pelo espelho?" (COCCIA, 2010, p. 25). Ambos entendem que "é sempre fora de si que algo se torna passível de experiência" (COCCIA, 2010, p. 20), e essa é uma das ideias, mas não a única, que faz a obra de Flávio de Carvalho tão atual.

"Existe um lugar onde as imagens nascem", escreve Coccia, após se perguntar sobre a possibilidade de existência de uma "ontologia do sensível". Pois Coccia conclui que é "produzindo sensível", sobretudo, que se produz efeito e influência sobre a realidade. E o sensível, ao mesmo tempo, é "o absolutamente transmissível" e também "o infinitamente apropriável" (COCCIA, 2010, p. 72), já que o homem não imita mais a Deus, e sim a si próprio. A restrição que Coccia faz a Lacan diz respeito a isso; segundo sua leitura, Lacan vê perigo no fato de o sujeito ser "sugado pela imagem", por meio da alienação e do fetiche, quando "a faculdade de reconhecer-se (ou de mal reconhecer-se) no sensível, de identificar-se com ele, de trocar-se por uma imagem, é ainda mais estranha e profunda, mais profana e cotidiana do que Lacan tentou isolar na assim chamada 'fase do espelho' (COCCIA, 2010, p. 57). Daí não causar espanto que seu ensaio se dedique não à literatura, tampouco à psicanálise, mas à moda, essa espécie de impensado das ciências humanas. 
O corpo que a roupa cria (já que a moda é outro corpo, um segundo corpo, exilado, que não coincide mais com o corpo anatômico) não é feito de carne e nem de qualquer outra matéria, mas de pura aparência. "A vestimenta humana é um corte no interior do corpo, não entre o corpo e seu exterior, mas sim entre um corpo anatômico e outro protético e puramente virtual. Roupa e corpo anatômico são duas realidades de um mesmo corpo.", escreve (COCCIA, 2010, p. 85). É por isso que a moda se apresenta com uma vida própria independente da consciência, da psicologia, ela é a pura mediação, e é por isso que o homem não faz, com a moda, a experiência do aberto, pois ele está aberto.

Flávio de Carvalho, à sua maneira, já havia entendido que a moda é um ente, uma pele, isto é, ela torna possível a experiência do sensível, já que a moda é também, e fundamentalmente, uma experiência. Em sua abordagem sobre a moda está em jogo uma espécie de vida própria da roupa, já descolada da intenção e da consciência. É possível imaginar as experiências de Flávio, tanto seus textos quanto suas performances, como experiências do novo, ou seja, do homem novo, que no caso é o homem em farrapos. Tanto para Flávio quanto para Coccia os conceitos de experiência e de sensível, ou de experiência e de moda, estão ligados de maneira definitiva.

\section{O novo homem}

O homem em farrapos, como foi dito, por meio do paradigma da exibição das pernas, estabelece uma linha de tensão entre o homem vestido e o homem nu. Quando Flávio de Carvalho escreve sobre o Unissexo, ou seja, o nivelamento entre masculino e feminino, o autor enfatiza justamente a exibição das formas nuas femininas, além da apropriação do traje do sexo oposto, como força criadora do novo. Flávio chega a sugerir uma relação entre a nudez e o comunismo: "O período do nu primitivo parece ser um período comunista: encontramos na alegria de viver da criança, que é um primitivo, muito do conteúdo psicológico do comunismo" (CARVALHO, 2010, p. 217). Ou seja, a sua teoria é do contato, não do isolamento. E a ideia de homem nu, em toda sua obra, dos desenhos aos retratos, traz inúmeras possibilidades de leitura - basta lembrar que Flávio é um dos artistas do século XX que mais representou a nudez. Mas é em um texto de 1930, mais de vinte anos antes de seus ensaios sobre moda, que a noção de nudez é elaborada.

Em "A Cidade do Homem Nu", acompanhado de Freud e Nietzsche, Flávio define com precisão, já nas primeiras linhas, o que é o homem nu: "homem do futuro, sem deus, sem propriedade e sem matrimônio" (CARVALHO apud LEITE, 2010, p. 69). E define também contra o que o homem nu deve se posicionar: "O homem perseguido pelo ciclo cristão, embrutecido pela filosofia escolástica, exausto com 1500 anos de monotonia recalcada, aparece ao nosso século como uma máquina usada, repetindo tragicamente os mesmos movimentos ensinados por Aristóteles" (CARVALHO apud LEITE, 2010, p. 69). Da mesma maneira que o homem em farrapos é a antítese do papa, o homem nu se coloca 
"fora do peso das tradições seculares", pois ele "precisa despir-se, apresentar-se nu, sem tabus escolásticos, livre para o raciocínio e o pensamento" (CARVALHO apud LEITE, 2010, p. 69). Impossível aqui não recordar a definição de moda segundo Boris Groys. O homem nu seria então a possibilidade de afirmar sua própria vida como um valor no tempo histórico, e se liberar do poder do passado (GROYS, 1995, p. 50)

A nudez, para Coccia, não se apresenta como uma dicotomia em relação à roupa, e sim como outra face de uma mesma faculdade. É graças à nudez, diz o filósofo, que somos capazes de alienar a nossa própria pele como um objeto exterior. E é graças também a ela que estamos condenados a trocar de pele, fazendo com que nenhuma roupa possa se transformar em natureza. Em outras palavras, a nudez é uma maneira de exílio e de experiência. "Estar nu significa ser capaz de alienar o próprio no impróprio e de assumir o impróprio como próprio" (COCCIA, 2010, p. 84). Para Flávio de Carvalho, por sua vez, o homem nu é um homem que "apresenta sua alma para pesquisas" (CARVALHO apud LEITE, 2010, p. 69), e nessa definição é possível antever todo um programa político que concilia moda, sensível e experiência. A moda será também uma forma de experiência. E o homem em farrapos, afinal, uma forma de vida.

Victor da Rosa Victor da Rosa é doutor em literatura pela UFSC e pós-doutorando pela UNESP de São José do Rio Preto (PNPD/Capes).

victordarosa@gmail.com

\section{Referências}

CARVALHO, F. A moda e o novo homem. Rio de Janeiro: Azougue Editorial, 2010.

Experiência n. 2. São Paulo: Nau, 2001.

Os ossos do mundo. São Paulo: Antiqua, 2004.

COCCIA, E. A vida sensível. Trad. Diego Cervelin. Desterro: Cultura e Barbárie, 2010.

GROYS, B. Du nouveau: essai d'économie culturelle. Nîmes: Éd. Jacqueline Chambon, 1995.

LEITE, R. M. Flávio de Carvalho. São Paulo: MAM, 2010.

SANGIRARDI JR. Flávio de Carvalho, o revolucionário romântico. Rio de Janeiro: Philobiblion, 1985. 